\title{
RESILIENT CITIES: MITIGATION MEASURES FOR URBAN DISTRICTS. A FEASIBILITY STUDY
}

\author{
DANILA LONGO, ANDREA BOERI, VALENTINA GIANFRATE, ELISABETTA PALUMBO \& \\ SAVERIA O.M. BOULANGER \\ Department of Architecture, University of Bologna, Italy.
}

\begin{abstract}
More than $70 \%$ of the European population live in cities, which are affected by several critical issues, such as the depletion of energy and material resources, decreasing of food security, increasing of greenhouse gas emissions levels with relevant environmental impacts and management issues (e.g. waste treatment). Urban areas emit about $80 \%$ of the global $\mathrm{CO}_{2}$ emissions and they are responsible for about $80 \%$ of global energy consumption.

Therefore, cities offer a possible action field for decisive local initiatives to address sustainability challenges, especially in terms of policy and societal actions, inspiring specific projects, which could be translated into more systematic programs at higher levels of governance. In order to mitigate climate change effects, the European energy policy is focused on buildings' energy efficiency due to its substantial savings' potential. This paper describes the integrated design approach developed by the Research Unit of the Department of Architecture of the University of Bologna, (RU) with the aim to identify scenarios of resilient actions for renovating existing buildings and districts, as well as for framing effective refurbishment design criteria at district level. This integrated approach combines energy efficient solutions and technologies, which have positive and sustainable impact on the environment with customer oriented strategies in order to ensure gains and customers' expectations and requirements at the same time.

The paper highlights: the link between mitigation strategies and the built environment; the application of the proposed Integrated Design Approach (IDA) inside the real context of Bolognina neighbourhood (Bologna, IT); the link between life cycle assessment (LCA), mitigation measures and IDA; analysis of results, impacts and potentialities of replication.

Keywords: climate change, mitigation strategies, built environment, integrated design approach, LCA.
\end{abstract}

\section{URBAN RESILIENCE AND CLIMATE CHANGE}

Nowadays a number of discussions are focused on the topic of cities and climate change. The international debate is aware of the urgent need to better understand the role of the city and its evolution into the future in order to encounter the increasing and pressing of the actual issues [1]. Overcrowding spaces, noise, poor air quality and related health problems, traffic congestion, waste production, water access and emissions from private cars, transport systems, buildings and industrial areas are just a few of the main issues that the cities have to deal, due to urban environment quality and resources' savings [2]. In fact, more than $70 \%$ of the European population live in cities [3], affected by several critical environmental issues, related to energy, material resources consumption, increasing levels of greenhouse gas emissions and lack of capacity to react in case of climate related events, both hazardous and not (heat islands, heat waves flooding, etc.). Therefore, lots of local actions are addressed to sustainability and resilience challenges, which constitute the basis for systematic programs at higher levels of governance [4].

As defined in the literature [5, 6], the main drivers of sustainable and resilient urban energy policies are: reductions of energy use; shifting from non-renewable to renewable sources of energy; moving towards closed-loop processes, such as combined heat/power systems fuel by methane from biological waste, where the waste stock from one process becomes feed 
stock for another one; creating distributed networks of energy production, moving the generation capacity closer to end-users and implementing demand-side policies that incorporate environmental and social externalities into the pricing mechanism; implementation of Climate Adaptation Plans for addressing soil permeability, evapotranspiration ratio and information technologies [7].

Even if mitigation and adaptation to climate change are both considered of great importance for making cities meet the transition toward low carbon and resilient, into this paper mitigation strategies are mainly focused.

According to Brown [8], Tyler [9] Davoudi [10] and Cartalis [11] resilience is assumed, for the purpose of this paper, as the ability of a system to react to stresses and shocks with relation to cities and climate change. Therefore, it is the capacity of urban systems to adequately react to unexpected events (extreme phenomena) and softer events (heat islands, energy peaks demand, etc.) as Pelling [12] and Vale [13] reminds. Hence, resilience assumes that climate change is occurring, recognizing uncertainty, change and crisis as normal but, instead of aiming to sustain the status quo, resilient strategies try to improve the ability of individuals, communities, or systems to recognize and adapt to disturbances, to overcome them and eventually come out stronger and transformed, changing the stability landscape [14] and creating new system pathways when ecological, economic or social structures make the existing system untenable, as elaborated by Pickett, Polese, et al. [15-18].

What makes a city resilient to natural and human-induced hazards can be seen as a combination of resiliences accumulated through the process of urbanization and planning and as the result of specific actions aiming to reduce disaster risks $[19,20]$. Research studies (also carried out by international organizations, such as FAO, NASA, UNEP), policies and European cities programs (i.e. cities of London, Copenhagen, Malmo, etc.) work in the direction of anticipating and mitigating the impacts of disasters, through monitoring activities and early warning technologies to protect infrastructure, community assets and individuals, including their homes and possessions, cultural heritage, environmental and economic capital, and is able to minimize physical and social losses arising from extreme weather events, earthquakes or other natural or human-induced hazards.

\section{BUILT ENVIRONMENT AND INTEGRATED DESIGN APPROACH FOR MITIGATION}

The Climate Change Mitigation is defined by the Intergovernmental Panel on Climate Change (IPCC) as the complex of actions dedicated to emissions reduction of greenhouse gasses [2]. The agreement, reached at the COP21 Paris climate change talks, is a great improvement on anything that has gone before: in a new global warming pact, countries set out milestones over the next five years in a bid to bridge the gap between national targets and what science recommends and, in particular, pursuing the containment below $2{ }^{\circ} \mathrm{C}$ of temperature increase. Then, the COP22 in Marrakech has enhanced this need, by underlining the necessity for states to put in practise Paris agreements as fast as possible, on a strong solidarity among countries perspective [21]. This target of lowering the increase of the average temperature has direct relations with the built environment and, in particular, with the energy consumption of buildings and with mitigation actions adopted by public administrations inside the built environment [22].

Hence, in urban areas, the built environment and the related energy processes highly affect the microclimate and cities are at the forefront of the most rapid environmental and climatic changes ever experienced, causing reduction in comfort and health and increasing buildings 
energy consumption [23]. In order to mitigate climate change effects, the European energy policy has placed great attention on buildings energy efficiency due to its substantial savings potential in: (1) the amount $\left(\mathrm{kWh} / \mathrm{m}^{2} \mathrm{y}\right)$ of energy for heating and cooling; (2) the amount of energy coming from renewables $\left(\mathrm{kWh} / \mathrm{m}^{2} \mathrm{y}\right) ;(3)$ the material typology and quality which reflect on LCA and $\mathrm{CO}_{2}$ emissions $(\mathrm{kg})$; (4) the amount $(\mathrm{kg})$ of $\mathrm{CO}_{2}$ emissions coming from energy use, anthropogenic activities inside buildings, materials, etc.; (5) the envelope quality which have great reflections on total urban anthropogenic heat, albedo, evapotranspiration rate, etc. [7, 24]. The aim is to reach "a suitable target for nearly zero-energy buildings", exploiting the mature level of technology, innovation, and effective tools, to obtain improvements in the efficiency of services, components and appliances $[25,26]$.

In this broad context, mitigation on the building sector can be defined as deploying and implementing design strategies, technologies and practices able to reduce energy demand and consumption of buildings - from design, construction, hand-over, renovation phase and end-of-life; switch to low- or no-carbon fuels; maximise opportunities for buildings to sequester carbon; catalyse behaviour change towards sustainable lifestyles [27].

Programs and regulations for existing building stock have mainly imposed minimum thermal behaviour and standards for energy efficiency [28], but the focus on efficiency has created a disjointed approach between the design of the building as an envelope and of its environmental control systems as mechanical add-ons, often leading to high up-front expenditures and to buildings designed as isolated systems. Despite a number of studies related to potential effects of refurbishment actions on the existing building stock [29], several technical and non-technical barriers occur and comprehensive strategies and measures focused on the interactions at the district scale are still lacking. For example, also building users' adaptive behaviour, expectations and potential active involvement in energy saving strategies are not sufficiently embedded into design process and building operation, increasing the 'performance gap' and missing the opportunity for further energy savings and consequent mitigation results [20]. The crucial point is to include mitigation strategies to climate change in the renovation strategies for existing buildings and districts, identifying resilient scenarios and design criteria at district scale. To bridge the gap between conventional renovation approaches and a multi-perspective vision of the transition needed to create a real low carbon environment, it's crucial to develop an Integrated Design Approach (IDA), fostering the coordinated application of scientific/technological, social and business innovations to develop solutions to the complex challenges of climate change. The holistic approach proposed is framed as a stepby-step process, considering the life cycle at a district scale as a key element to foster the effectiveness of urban mitigation.

Integrated Design Approach [IDA] is based on the following tasks:

- identification of the critical constraints (e.g. legal, non-technical);

- identification of the human behaviour constraints or propensity to improve mitigation technical solution;

- definition of a multi-scale and multi-criteria matrix of parameters to model the effects of each renovation option at building scale on the overall scenario at district scale;

- $\quad$ setting-up of the key parameter for achieving high quality standards;

- strategy definition and assessment of possible configurations of district adjacent systems;

- assessment of the impacts of the whole neighbourhood (buildings, grid etc.) on the "individual building" as basis for modelling and integration in the tools;

- economic and environmental assessment of the measures; 
- comparative assessment of the different scenario with relation to energy efficiency and share of renewable;

- analysis of the energy balance between Embodied Energy and Operational Energy Assessment in the building through the life cycle approach.

The achievement of reliable, affordable, available and comparable data is based on clear indicators concerning performances at building and district level capable of collecting and managing many factors (economic aspects, technical choices, legal and social context, etc.), to perform multi-criteria analysis and select the most suitable strategies' alternatives according to optimized savings and budget constraints (Fig. 1).

The multi-criteria analysis, presented in figure above, allows speeding up the process assessing several alternatives at the same time, accordingly to common and comparable parameters (such as $\mathrm{kg}$ of $\mathrm{CO}_{2}$ emissions, $\mathrm{kWh} / \mathrm{m}^{2} \mathrm{y}$, etc.). This will ensure the prioritisation of actions and it will enable integrated mitigation strategy planning to meet local requirements by a number of opportunities such as:

- lowering resources use across the entire community involved at district level;

- improving the resource efficiency and performance of buildings/district in the operational environment and during extreme events;

- reducing the operational costs and speed-up the process to improve the sustainability of the renovation actions.

This integrated and holistic design is adopted to overcome known barriers and to support the achievement of the following main objectives:

- defining key design parameters and interrelation between buildings at district scale, by the mean of clear and measurable factors (considering the specific climate conditions), to develop mitigation actions and improving at the same time comfort conditions and costeffectiveness;

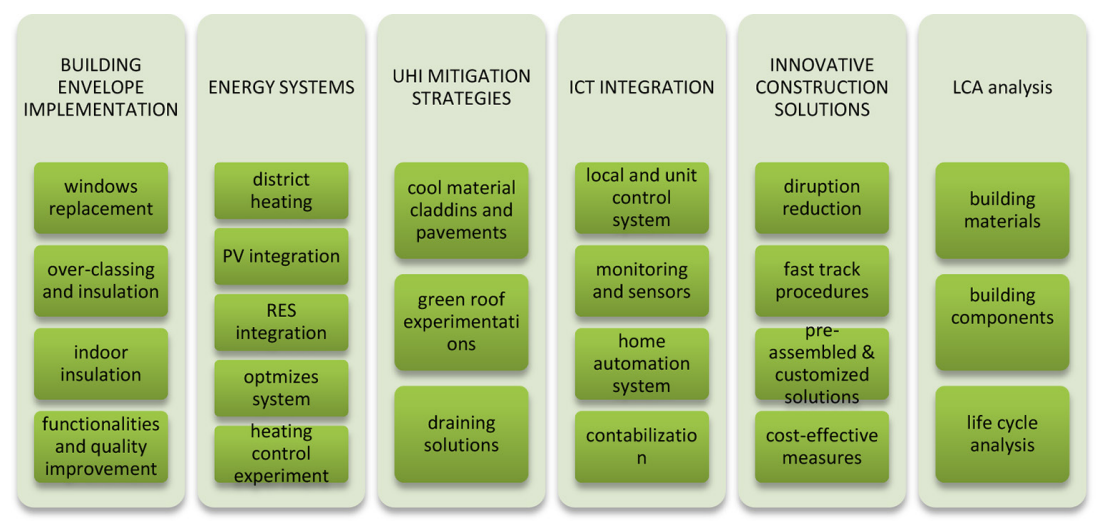

Figure 1: Integrated design steps to foster the integration between building retrofitting and mitigation measures 
- developing design and management settings to be applied in the operational environment: design strategies (at building and district scale), technical solutions (for heating/cooling, ventilation, domestic hot water production, renewable energy sources, thermal storage, electrical energy production and distribution, building envelope systems, building components), construction processes, building management system/district management system;

- identifying adequate geo-clusters in order to manage the complexity of the existing building stock and to obtain a homogeneous set of aggregated data to be used as key indicators in large-scale interventions (from the building to the district to the city).

In this iterative approach, each option is carefully evaluated according to specific parameters and to its coherence with the action as a whole.

In the next section, a IDA feasibility study for the real context of Bolognina (Bologna, IT) neighbourhood is presented.

\section{A FEASIBILITY STUDY FOR BOLOGNINA NEIGHBOURHOOD}

The Research Unit of the Department of Architecture, University of Bologna (RU) is currently involved in the definition of a coherent, articulated and replicable strategy for Bologna social housing stock, to support the Municipality in the achievement of integrated technical solutions to act renovation measures in a reasonable timeframe with a limited disruption for the end-users.

The RU follows the IDA, described in the above paragraph, to identify resilient scenarios for renovating existing buildings and districts and for framing effective refurbishment design criteria at district scale.

The adoption of this process has allowed to obtain qualitative and quantitative results and to create an integrated design framework for decision support in demonstration projects finalized to improve the mitigation potential at different levels.

The deep-retrofit feasibility study is applied in the Bolognina Neighbourhood, a 1920s/1960s social housing neighbourhood, inside the Navile district, with high replication potential, considered strategic for its infrastructures, services, and proximity with historical city centre, characterized by a large number of public residential units, affected by obsolescence and high energy consumptions [31].

The aim of this study is addressed to facilitate and speed up innovative actions for energy renovation and resilience enhancement at the district scale in order to boost transition towards more resilient and efficient environment throw well-balanced and cost-effective deep energy measures.

The study has included the following activities, applying the IDA for:

1. identification of barriers to the application of district concept and proposals for regulation amendments - where needed - to policy makers;

2. identification of the key design indicators [6] and interrelation between them at district scale, accordingly to clear and measurable factors (taking into consideration the specific climate conditions, evaluated through simulations by ENVI-met Software [24] (Fig. 2) and on the basis of Bologna Climate Adaptation Plan [32-34]), to develop strategies and mitigation actions for comfort conditions improving and to identify preliminary strategies to achieve these targets to a sub-optimal design solution tailored for the specific demonstrators; 
3. definition and adoption of specific design and management protocols (aiming at a combination of resource efficiency measures with cost-effective standards at district level) to be applied in the operational environment, (with a specific focus on three building blocks) able to limit the tenants' disruption (1 day), assumed as a key element to deliver the renovation in this specific socio-economic context. The reduction of construction time by adopting standardized assembled construction systems is also aimed at reducing the disruption for the end-users;

4. integration between hardware strategies for refurbishment and ICT devices, sensors and dashboards, to accomplish the achievement of a more effective (also adopting remote control systems) management of the building stock, at district and urban scale;

5. definition of cost-effective retrofitting strategies (comparing retrofitting costs and energy lifetime and finding the optimum) through efficient building envelope, application of technologies for refurbishment, and careful consideration of materials in a LCA vision;

6. mitigation of climate conditions (UHI effects) as a key part of the refurbishment strategy, with the aim of increasing indoor and outdoor comfort conditions by adopting facade components (green extensions, solar collectors) as shading systems and thermal regulators, obtaining a mitigation effect to the risk of overheating during summer time and improving the building behaviour against more frequent extreme weather conditions;

7. integration of active solar gains (PV panel and solar collectors) into buildings which are assumed as "prosumers", transforming very conventional and energy consuming volumes into efficient nodes of an integrated smart grid.

The main indicators include: economical aspects (life cycle cost), environmental aspects (energy, materials, waste of refurbishment operations); social aspects (climate conditions, safety and accessibility, comfort, usability, cultural value), technical aspects (building components, systems, integration with grids).

The definition and evaluation of indicators follow a LCSA approach, adopting the same procedure of the Environmental LCA, (ISO 14040 and ISO 14044 standards for Life Cycle Assessment). It is articulated into different phases: goal and scope definition, life cycle inventory analysis, life cycle impact assessment, interpretation, etc. This sequence is useful to analyze the systems, the functional units, the relevant indicators, and impact categories, as well as to support data collection and analysis of hotspots.

\section{LCA AT DISTRICT LEVEL}

In order to reduce the life cycle energy consumption of buildings and therefore reducing emissions and help preventing global warming caused by greenhouse gases, most attention has therefore been paid to the operation phase. In fact, the importance of evaluating and managing $\mathrm{CO}_{2}$ emissions generated by buildings is crucial, as highlighted in [35]. For mitigating building $\mathrm{CO}_{2}$, it is necessary to consider both direct and indirect emissions throughout the whole building life cycle, which also include production, construction, operation, and end-oflife stages [35]. As well, it is necessary to include materials and component production applied on buildings (e.g. bricks, steel, glazing, etc.). Buildings and related products are, in fact, realized with a variety of materials and each material consumes energy during different stages: manufacture, use and deconstruction/demolition phases [36]. This implies that global efforts to reduce emissions in buildings cannot be totally achieved by ignoring the embodied energy. Consequently, as regards these stages of the entire Life Cycle, we have focused on the 

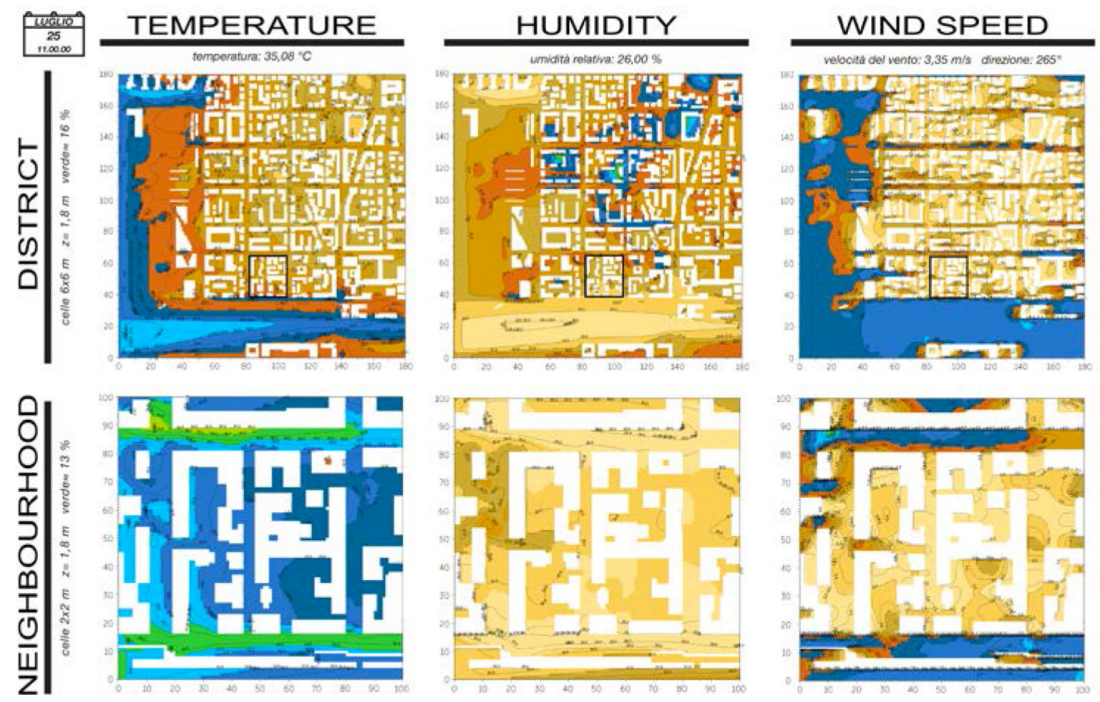

Figure 2: Specific simulations about climate conditions (especially linked with Urban Heat Island, Humidity, Wind velocity) elaborated through Envimet software).

embodied energies and global $\mathrm{CO}_{2}$ emissions calculated for the product stage, that includes raw material supply (A1), transport of materials from extraction to manufacturing site (A2), and manufacturing itself (A3). These information are those usually available in the Environmental Product Declaration (EPD) of products on the market, and on the basis of these environmental indicators we have defined the technical solutions for the refurbishment.

Therefore, in the feasibility study, the influence of building material choice on the embodied environmental impacts was taken into consideration, together with environmental benefits and material costs for Social Housing refurbishment in Bologna. The aim was to calibrate the performance of buildings in terms of both embodied and operational emissions in order to reduce total life cycle emissions.

The effects of the choice were studied for the three building component categories: envelope frame, transparent components, and multi-layers components (i.e. insulation) in a comparative way, based on the analysis of the reduction of $\mathrm{CO}_{2}$ emissions; recycling potential; and reduction of emissions embodied in the materials used in the retrofitting and maintenance.

Bolognina building stock requires a comprehensive renovation strategy capable of increasing energy performance, improving quality of living and comfort conditions, and implementing innovative energy and environmental assessment methodologies, based on LCA and including also non-monetary aspects in the cost/benefit and pay-back analysis.

This study has paved the way for the new field of an integrated assessment of the built environment at the neighbourhood scale using LCA approaches: in fact the built environment is considered as the summation of all human-made structures, infrastructure and transportation systems.

Recently a new trend stems in the application of LCA to neighbourhood projects as an answer to this growing interest for sustainability investigation and planning at the neighbourhood scale 
[37]. The future aim is to contribute to the development of a standardized approach for assessing the environmental performance of the built environment at the neighbourhood scale.

\section{RESULTS, IMPACTS AND POTENTIALITY OF REPLICATION}

The RU feasibility study has developed an open and easily replicable strategy for designing, constructing, and managing urban mitigation projects to achieve sustainable cities, based on the following pillars:

- studies of cost-effective solutions for the holistic improvement of the performance of buildings at district level (definition of standard indicators and new diagnosis approach, analysis of existing technologies in a systemic approach, identification of mitigation strategies for the built environment) to improve their resilience and their resource efficiency;

- deployment of a rigorous measurement and verification of energy performance and savings plan for each demonstrator, taking into account standard protocols, energy regulations, LCA approach.

The RU has defined a quick and effective detection of the propensity of elements composing the district (from buildings to grids) to be improved, and it has allowed the scheduling of the envisaged actions being aware of the potential deriving impacts in terms of energy efficiency, costs and achievable comfort level (Fig. 3). The three buildings, objects of experimentation, have achieved an energy consumption reduction close from $60 \%$ to $80 \%$, with cost-effective and fast-track solutions (Table 1).

This result could have a huge potential impact for different target groups [38], such as:

- PAs to boost the renovation rate of their stock (according to EU Directive 2012/27);

- real estates to assess the effectiveness of their action plan in terms of payback on large scale projects;

- energy supplier and ESCO to promote integrated measures including building envelope implementation and RES with customized energy contracts;

- district and citizen communities, to facilitate the creation and adoption on voluntary basis of groups of purchase for energy supply, retrofitting actions, etc.

This feasibility study is expected to produce significant positive impacts on the sustainability at district and urban scale:

- in the short term, it will drive innovations in energy efficiency management and control technologies in the field of refurbishment and will increase the key player awareness generating a greater demand for innovative retrofit solutions (e.g. insulation, ventilation, water saving, etc.) at building scale and for integrated measures at district scale;

- in the medium term, it will address renovation projects to a coordinated vision adopting the results as a model to be replicated in a flexible way, with the aim to re-designing/reengineering other urban areas according to a more climate resilience perspective.

Next steps for future research branches will be addressed to study effective solutions that allow buildings, located in a district, to interact each other and with their immediate urban infrastructures. The combination of future-oriented energy concepts with feasible technical 


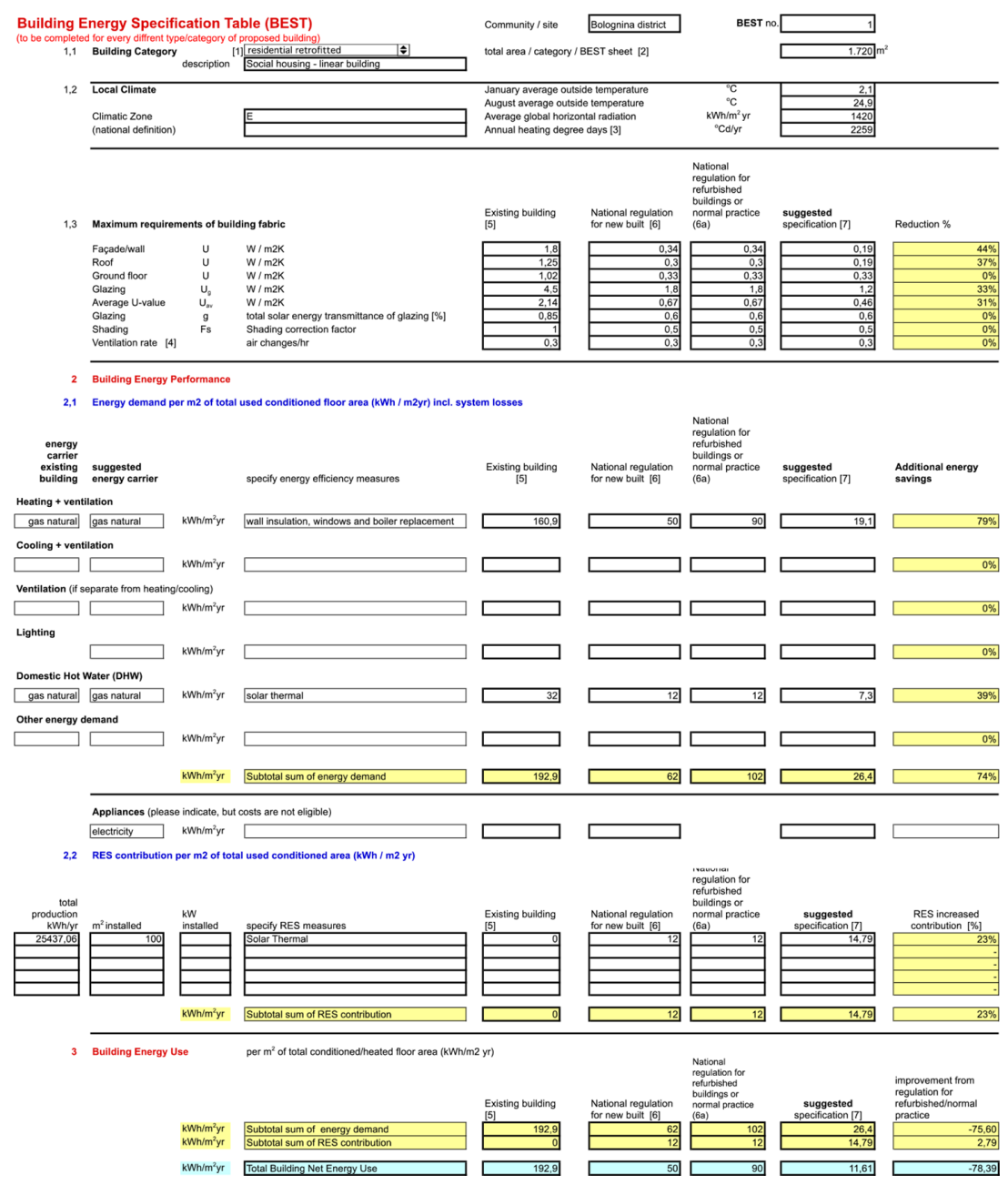

Figure 3: The data sheet (following the H2020 Building Energy Specification Table format) related to one of the three demo-buildings, to highlight the different contributes to the effectiveness of the renovation strategy.

Table 1: The synthesis of the results obtained from the simulation on the three buildings

Energy saved (in respect to

Building Total Surface IT regulation) RES contribution CO2 savings (kg)

\begin{tabular}{lllll}
\hline 1 & $1.720 \mathrm{~m}^{2}$ & $75,60 \mathrm{kWh} / \mathrm{m}^{2} \mathrm{y}$ & $2,79 \mathrm{kWh} / \mathrm{m}^{2} \mathrm{y}$ & $62599 \mathrm{~kg}$ \\
2 & $2.702 \mathrm{~m}^{2}$ & $79,59 \mathrm{kWh} / \mathrm{m}^{2} \mathrm{y}$ & $4,64 \mathrm{kWh} / \mathrm{m}^{2} \mathrm{y}$ & $125590 \mathrm{~kg}$ \\
3 & $1.005 \mathrm{~m}^{2}$ & $72,47 \mathrm{kWh} / \mathrm{m}^{2} \mathrm{y}$ & $10,26 \mathrm{kWh} / \mathrm{m}^{2} \mathrm{y}$ & $41470 \mathrm{~kg}$ \\
\hline
\end{tabular}


and architectural solutions could answer to the new quality requirements for sustainable districts and cities.

The adopted methodology is addressed to define scaling-up and replication rules (Fig. 5), which allows to address different district sizes, climatic zones and different energy regulatory regimes.

This high replication potential is demonstrated by the presence of 11889 flats of affordable housing into the city centre, with the $38,31 \%$ of building realized before 1958 , and currently in need of integrated renovation. The scaling up methodology is articulated in the definition of retrofitting strategies for different residential building typology (isolated, multi-storey, courtyards buildings, etc.) and in the development and testing of energy "interface" between buildings and urban fabric, to foster optimal energy efficiency in a larger perspective.

The transition process to mitigate built environment has to be supported by adequate replication models capable of improving the flexibility/adaptability of the methodology pointed up: new functionalities and new potential application will support the change, contributing to a constant exchange of information between stakeholders, improving the management of buildings and their surrounding environment, in a easier and faster renovation of practice. This methodology has the main goal to accelerate the Climate Adaptation Plan of the Municipality of Bologna [39], related to building sector, promoting in the transition to more resilient urban districts, and supporting the creation of a community of practice composed by University, Municipality, the Public Real Estate Agency, and tenants' groups of interest.

\section{REFERENCES}

[1] European Environment Agency, Urban adaptation to climate change in Europe. Challenges and opportunities for cities together with supportive national and European policies, report $n^{\circ} 2 / 2012,2012$. Available at: http://www.eea.europa.eu/publications/urbanadaptation-to-climate-change. (accessed 17 February 2017).

[2] IPCC, Climate Change 2014. Synthesis Report. Contribution of Working Groups I, II and III to the Fifth Assessment Report of the Intergovernmental Panel on Climate Change [Core Writing Team, R.K. Pachauri \& L.A. Meyer (eds.)]. IPCC, Geneva, Switzerland, 151 pp., 2014. Available at: http://www.ipcc.ch/report/ar5/wg2/. (accessed 17 February 2017).

[3] World Population Prospects-United Nations Population Division, 2009. Available at: http://www.un.org/esa/population/publications/wpp2008/wpp2008_highlights.pdf. (accessed 17 February 2017).

[4] Roorda, C. \& Wittmayer, J., Transition management in five European cities. an evaluation. DRIFT, Erasmus University Rotterdam, Rotterdam, 2014.

[5] UN Habitat. Planning Sustainable Cities: Global Report on Human Settlements. London, Earthscan, 2009.

[6] OECD, Competitive Cities and Climate Change. Organization for Economic Co-operation and Development, Paris, 2009.

[7] European Commission Directorate General. LIFE and Climate change adaptation, Luxembourg, 2015. Available at: https://ec.europa.eu/clima/sites/clima/files/docs/life_ climate_change_adaptation_en.pdf. (accessed 17 February 2017).

[8] Brown, E.D. \& Byron, W.K., Resilience and resource management. Environmental Management, 56(6), pp. 1416-1427. https://doi.org/10.1007/s00267-015-0582-1 
[9] Shaw, K., "Reframing" resilience: challenges for planning theory and practice. Planning Theory \& Practice, 13(2), pp. 308-312, 2012.

[10] Davoudi, S., Resilience: a bridging concept or a dead end? Planning Theory \& Practice, 13(2), pp. 299-307, 2012.

[11] Cartalis, C., Toward resilient cities - a review of definitions, challenges and prospects. Advances in Building Energy Research, 8(2), pp. 259-266, 2014. https://doi.org/10.1080/17512549.2014.890533

[12] Pelling, M., Adaptation to climate change: from resilience to transformation. Routledge, London, 2010.

[13] Vale, L.J. \& Campanula, T.J., The Resilient City: How modern cities recover from disaster, Oxford University Press, Oxford, 2005.

[14] Gallopín, C., Linkages between vulnerability, resilience, and adaptive capacity, Global Environmental Change, 16(3), pp. 293-303, 2006. https://doi.org/10.1016/j.gloenvcha.2006.02.004

[15] Pickett, S.T.A, Cadenasso M.L. \& Grove, J.M., Resilient cities: meaning, models, and metaphor for integrating the ecological, socio-economic and planning realms. Landscape and Urban Planning, 69, pp. 369-384, 2003. https://doi.org/10.1016/j.landurbplan.2003.10.035

[16] Polese, M., The Resilient City: On the determinants of successful urban economies (Working Paper no 2010-03). Centre - Urbanisation Culture Societe, INRS, University of Quebec, Montreal.

[17] Leichenko, R., Climate change and urban resilience. Current Opinion in Environmental Sustainability, 3, pp. 164-168, 2011. https://doi.org/10.1016/j.cosust.2010.12.014

[18] Jabareen, Y., Planning the resilient city. Cities, 31, pp. 220-229, 2013. https://doi.org/10.1016/j.cities.2012.05.004

[19] The United Nation Office of Disaster Risk Reduction, Making Cities Resilient Report 2012. My city is getting ready! A global snapshot of how local governments reduce disaster risk, 2012. Available at: http://www.unisdr.org/files/28240_rcreport.pdf. (accessed 18 February 2017)

[20] Godschalk, D.R., Urban hazard mitigation: creating resilient cities. Plenary paper presented at the Urban Hazards Forum, John Jay College, City University of New York, January 22-24, 2002. Available at: http//www.arch.columbia.edu/Studio/Spring2003/ UP/Accra/links/GodshalkResilientCities.doc

[21] Marrakesh Action Proclamation for our climate and sustainable development, 2017. Available at: http://unfccc.int/files/meetings/marrakech_nov_2016/application/pdf/ marrakech_action_proclamation.pdf. (accessed 18 February 2017).

[22] Santamouris, M., Innovating to zero the building sector in Europe: Minimising the energy consumption, eradication of the energy poverty and mitigating the local climate change. Solar Energy, 128, pp. 61-94, 2016. http://doi.org/10.1016/j.solener.2016.01.021

[23] Stone, D., Allen, M.R., Selten, F., Kliphuis, M. \& Stott, P.A., The detection and attribution of climate change using an ensemble of opportunity. Journal of Climate, 20, pp. 504-516, 2007.

https://doi.org/10.1175/jcli3966.1

[24] Evyatar, E., David, P. \& Terry, W., Urban Microclimate. Designing the Spaces between Buildings. Earthscan, London, 2011. 
[25] ECOFYS, Towards nearly zero-energy buildings. Definition of common principles under the EPBD Final report - Executive Summary, European Commission, 18 March 2013.

[26] Monfaredzadeh, T. \& Berardi, U., How can cities lead the way towards a sustainable, competitive and smart future? WIT Transactions on Ecology and the Environment, (January), pp. 1063-1074, 2014. http://doi.org/10.2495/SC140902

[27] Wynn Chi-Nguyen Cam, Technologies for Climate Change Mitigation - Building Sector, TNA Guidebook Series, UNEP, September 2012.

[28] Allegrini, J., Kamof, J., Dorer, V. \& Carmeliet, J., Modelling the urban microclimate and its influence on building energy demands of an urban neighbourhood. CISBAT 2013, Lausanne, Switzerland, 2013.

[29] Hrabovszky-Horváth, S., Pálvölgyi, T., Csoknyai, T. \& Talamon, A., Generalized residential building typology for urban climate change mitigation and adaptation strategies: The case of Hungary. Energy and Buildings, 62, pp. 475-485, 2013. http://dx.doi.org/10.1016/j.enbuild.2013.03.011

[30] Janda, K.B., Buildings don't use energy: people do. Architectural Science Review, 54(1), pp. 15-22, 2011. https://doi.org/10.3763/asre.2009.0050

[31] Antonini, E., Boulanger, S. O. M., \& Gaspari, J., Multi-layered urban strategies to foster the Smart Cities development. Tenth International Conference on Urban Regeneration and Sustainability, 194, pp. 23-34, 2015. http://doi.org/10.2495/SC150031

[32] Comune di Bologna. PAES piano d'azione per l'energia sostenibile, 2013. Available at: http://www.paes.bo.it/

[33] Comune di Bologna. Profilo Climatico Locale. Analisi delle vulnerabilità all'impatto dei cambiamenti climatici, Bologna, 2015.

[34] Urban Center Bologna, \& Comune di Bologna. Bologna città resiliente. Sostenibilità energetica e adattamento ai cambiamenti climatici (I Quaderni). Urban Center, Bologna, 2016.

[35] Seungjun, R. \& Sungho, T., An integrated assessment system for managing life cycle CO2 emissions of a building. Renewable and Sustainable Energy Review, 73, pp. 265275, 2017. https://doi.org/10.1016/j.rser.2017.01.139

[36] Dixit, M.K., Fernandez-Solis, J.L., Lavy, S. \& Culp, C.H., Need for an embodied energy measurement protocol for buildings: a review paper. Renewable and Sustainable Energy Reviews, 16, pp. 3730-3743, 2012. https://doi.org/10.1016/j.rser.2012.03.021

[37] Lotteau, M., Loubet, P., Pousse, M., Dufrasnes, E. \& Sonnemann, G., Critical review of life cycle assessment (LCA) for the built environment at the neighborhood scale. Building and Environment, 93, pp. 165-178, 2015. https://doi.org/10.1016/j.buildenv.2015.06.029

[38] Boeri, A., Gianfrate, V., Longo, D. \& Palumbo, E., Transition to sustainable city: an integrated design approach for transformative districts. a proposal for replicability. WIT Transactions on Ecology and the Environment, WIT Press, 2015 ISBN 978-1-84564-942-5.

[39] Piano di adattamento Città di Bologna, Municipality of Bologna, 2015. Available at: http://www.blueap.eu/site/wp-content/uploads/2015/06/PianoBlueApfinale03062015.pdf 